Hydrol. Earth Syst. Sci. Discuss., https://doi.org/10.5194/hess-2018-447

Manuscript under review for journal Hydrol. Earth Syst. Sci.

Discussion started: 12 November 2018

\title{
Using Snowfall Intensity to Improve the Correction of Wind-Induced Undercatch in Solid Precipitation Measurements
}

\author{
Matteo Colli ${ }^{1,2}$, Mattia Stagnaro ${ }^{2,3}$, Luca Lanza ${ }^{2,3}$, Roy Rasmussen ${ }^{4}$ and Julie M. Thériault ${ }^{5}$
}

$5{ }^{1}$ Electrical, Electronics and Telecommunication Engineering and Naval Architecture Department, University of Genoa, Genoa, 16145, Italy

${ }^{2}$ WMO/CIMO Lead Centre “B. Castelli” on Precipitation Intensity, Genoa, 16145, Italy

${ }^{3}$ Department of Civil, Chemical and Environmental Engineering, University of Genoa, Genoa, 16145, Italy

${ }^{4}$ Department of Earth and Atmospheric Sciences, Université du Québec à Montréal, Montreal, H2X 3Y7, Quebec, Canada

$10{ }^{5}$ Research applications Laboratory, National Center for Atmospheric Research*, Boulder, 80307-3000, Colorado, USA

Correspondence to: Matteo Colli (matteo.colli@unige.it)

\begin{abstract}
Transfer functions are generally used to adjust for the wind-induced undercatch of solid precipitation measurements. These functions are derived based on the variation of the collection efficiency with wind speed for a particular type of gauge, either using field experiments or based on numerical simulation. Most studies use the wind speed

15 alone, while others also include surface air temperature and/or precipitation type to try to reduce the scatter of the residuals at a given wind speed. In this study, we propose the use of the measured precipitation intensity to improve the effectiveness of the transfer function.

This is achieved by applying optimized curve fitting to field measurements from the Marshall field-test site (CO, USA). The use of a non-gradient optimization algorithm ensures optimal binning of experimental data according to the parameter under

20 test. The results reveal that using precipitation intensity as an explanatory variable significantly reduce the scatter of the residuals. The scatter reduction as indicated by the Root Mean Square Error (RMSE) is confirmed by the analysis of the recent quality controlled data from the WMO/SPICE campaign, showing that this approach can be applied to a variety of locations and catching-type gauges.
\end{abstract}

We demonstrate the physical basis of the relationship between the collection efficiency and the measured precipitation

25 intensity, due to the correlation of large particles with high intensities, by conducting a Computational Fluid-Dynamics (CFD) simulation. We use a Reynolds Averaged Navier-Stokes SST k- $\omega$ model coupled with a Lagrangian particle-tracking model. Results validate the hypothesis of using the measured precipitation intensity as a key parameter to improve the correction of wind-induced undercatch.

Findings have the potential to improve operational measurements since no additional instrument other than a wind sensor is

30 required to apply the correction. This improves the accuracy of precipitation measurements without the additional cost of ancillary instruments such as particle counters.

\footnotetext{
${ }^{*}$ The National Center for Atmospheric Research is sponsored by the National Science Foundation
} 
Hydrol. Earth Syst. Sci. Discuss., https://doi.org/10.5194/hess-2018-447

Manuscript under review for journal Hydrol. Earth Syst. Sci.

Discussion started: 12 November 2018

(c) Author(s) 2018. CC BY 4.0 License.

\section{Introduction}

Precipitation measurements from catching type gauges are affected by instrumental and environmental errors. Among the environmental factors, wind plays a dominant role by reducing the gauge collection ability, especially in case of solid precipitation (Goodison et al, 1998; Rasmussen et al., 2012).

5 Over the past two decades, Computational Fluid-Dynamic (CFD) simulations have been used to evaluate the wind-induced undercatch of traditional catching type gauges (Nespor and Sevruk, 1999; Constantinescu et al., 2006; Thériault et al., 2012). A recent analysis by Colli et al. (2015) showed good agreement between the collection efficiency predicted by time averaged models and field observations made at the NCAR/NOAA/FAA Marshall Field Test site (CO, USA, Rasmussen et al. 2012). In the latter case, the collection efficiency $C E(-)$ is expressed as the ratio between the precipitation amount measured by the

10 tested gauge $P(\mathrm{~mm})$ and a Double Fence International Reference (DFIR) shielded gauge $P_{D F I R}(\mathrm{~mm})$.

Given the systematic nature of this environmental error, correction methodologies (e.g. Yang et al., 1995) have been mainly based on establishing algebraic relationships between $C E$ and the mean wind speed $U_{w}\left(\mathrm{~ms}^{-1}\right)$, also referred to as transfer functions. Thériault et al. (2012) and Colli et al. (2015a) specified collection efficiency variation with wind speed for different solid precipitation types and particle size distributions. Wolff et al. (2015) proposed a sigmoidal variation of the

15 collection with wind speed using the observations collected in Haukeliseter (Norway), which includes the environmental temperature $T\left({ }^{\circ} \mathrm{C}\right)$ as an additional parameter to account for the effect of the precipitation type. A recent paper by Kochendorfer et al. (2017a) describes a simplified inverse exponential formulation for the universal transfer function as follows:

$$
C E=e^{-a\left(U_{w}\right)\left(1-\left[\tan ^{-1}(b(T))+c\right]\right)}
$$

20 where $a, b$ and $c$ are coefficients derived by fitting the field data. The analysis of Kochendorfer et al. (2017a,b) is based on measurements collected at the Marshall field site and highlighted that, while a transfer function can reduce the gauge's bias to near zero, a large RMSE still remains. Theriault et al (2012) suggest that the large RMSE is due to variability in the particle type and size distribution of solid precipitation. Another recent experiment conducted in Formigal (Spain) within the framework of the World Meteorological Organization (WMO) SPICE - Solid Precipitation InterComparison Experiment

25 (Nitu et al., 2012) showed that "the impact of temperature and snowfall intensity on the catch ratio was less important than wind speed, but still noticeable (...)” (Buisan et al., 2016).

Colli et al. (2015) presented dry snow $C E$ estimations for an unshielded and a single Alter (Alter, 1934) shielded gauges based on data from the Marshall field site. The comparison of CFD simulations and the observations (Figure 8 of Colli et al., 2015) highlights that a large part of the CE variability for a given wind speed is explained by the particle size distribution.

30 Thériault et al. (2012 and 2015) reported that the catching performance of a shielded gauge is also significantly related to the vertical velocity of the particles approaching the gauge. The particle size distribution and vertical velocity contribute to the calculation of the measured snowfall intensity $S I\left(\mathrm{mmh}^{-1}\right)$ as follows: 
Hydrol. Earth Syst. Sci. Discuss., https://doi.org/10.5194/hess-2018-447

Manuscript under review for journal Hydrol. Earth Syst. Sci.

Discussion started: 12 November 2018

(c) Author(s) 2018. CC BY 4.0 License.

(c) (i)

Hydrology and

Earth System

Sciences

Discussions

$$
S I=\alpha \int_{D_{\min }}^{D_{\max }} N(D) \cdot w_{p}(D) \cdot D^{3} d D
$$

where $D$ is the particle diameter $(\mathrm{mm}), N(D)$ the number of particles with diameter $\mathrm{D}, \mathrm{w}_{\mathrm{p}}(D)$ their vertical velocity $\left(\mathrm{m} \mathrm{s}^{-1}\right)$ and $\alpha$ a factor that accounts for the shape of the snowflake.

Given the challenges to decrease the RMSE of the collection efficiency variation with wind speed, the goal of this study is to

show the dependence of the gauge collection efficiency on snowfall intensity. Previous studies (e.g. Folland, 1988; Nespor and Sevruk, 1998), focused on liquid precipitation, specified the functional relationships between wind-induced undercatch and $U_{w}$ for different rainfall rate classes. Following a similar approach, the here investigated formulation of $C E$ is a modified version of the relationship proposed by Kochendorfer et al. (2017) obtained by substituting the air temperature with $S I$ as follows:

$$
C E=e^{-a\left(U_{w}\right)\left(1-\left[\tan ^{-1}(b(S I))+c\right]\right)}
$$

10

where $a, b$ and $c$ are numerical best-fit coefficients.

This approach is first developed by considering snow gauge data collected at the Marshall (CO, USA), CARE (Canada) and Haukeliseter (Norway) field-test sites. Second, the results are compared with CFD modelling.

The measurements and the data processing method used to perform the field data analysis are presented in section 2. Section

153 reports on the observed correlation between $C E$ and either the measured snowfall intensity or the environmental temperature. A description of the data binning optimization according to SI is also included. The influence of the chosen time-average period for measurement on the collection efficiency is described in section 4 . In section 5 the dependency between the $C E$ and the measured snowfall intensity is investigated using CFD simulations with the aim of providing a physical basis for the correlation observed in section 3.

\section{Methodology of field data analysis}

\subsection{Field data processing}

The development and testing of new methodologies to retrieve the $C E$ requires the availability of quality controlled meteorological measurements at high time resolution from a properly instrumented test bed. The solid precipitation measurements used in this study were collected by a single Alter and a DFIR shielded Geonor T200B with a 6-second sampling time at the Marshall field site (CO, USA, Rasmussen et al., 2012). This period covers the WMO SPICE data collection period and is characterized by the availability of ancillary data to support investigation into factors such as wind speed and precipitation intensity as well as high levels of data scrutiny and quality control. Ancillary data are collected every minute. The single Alter (SA) Geonor T200B gauge measurements are compared to those made by the DFIR shielded Geonor T200B gauge that was defined as the working automated reference for WMO-SPICE (Kochendorfer et al., 2017c). 
Hydrol. Earth Syst. Sci. Discuss., https://doi.org/10.5194/hess-2018-447

Manuscript under review for journal Hydrol. Earth Syst. Sci.

Discussion started: 12 November 2018

(c) Author(s) 2018. CC BY 4.0 License.

Wind speed is measured at 2-m above the surface using a propeller anemometer (Model 05103 Wind Monitor, RM Young) whereas the temperature is at $1.5 \mathrm{~m}$ above the surface using a fan-aspirated (Model 076B Radiation Shield, Met One Instruments) platinum resistance thermometers (Model CS500-L, Campbell Scientific).

GEONOR weighing gauges are based on vibrating wire technology. Noise in the output is due to environmental factors that

5 cause oscillations of the measuring bucket. These effects have been limited by post-processing the 6-sec gauge time series with a Gaussian Linear Time Invariant (LTI) filter characterized by a filtering window equal to 2 min and a standard deviation equal to $1 \mathrm{~min}$. A correction of the vibrating wires sensitivity to the environmental temperature has been applied as well. In addition, an automatic quality control has been performed to check the occurrence of missing data, decreasing trends or jumps in the precipitation time series and in-consistent records among by the three vibrating wires of the Geonor

10 T200B gauges (Reverdin, 2016).

The measured CE is expressed as the ratio between the precipitation amount measured by the tested gauge and a Double Fence International Reference (DFIR). For the sake of highlighting any dependency between the collection efficiency and the snowfall intensity measured by the uncorrected gauge, the analysis reported in Section 3 is focused on a subset of 30 min measurements made at the Marshall field site that have been selected and quality controlled by the WMO SPICE procedures

15 described in Reverdin (2016) and Kochendorfer et al. (2017b). This time period is short enough to represent the time variability of precipitation type, temperature and wind speed, and not too long to exclude changes in meteorological conditions (Kochendorfer et al., 2017). On the other hand, the 30-min time period is considered long enough to accumulate snowfall amounts that can be measured by the snow gauges. Furthermore, the sample is composed exclusively by measurements performed when the reference (DFIR) precipitation amount is higher or equal to $0.25 \mathrm{~mm}$ over the $30 \mathrm{~min}$

20 interval to reduce the effects of measurement noise. The period considered by such dataset starts from October 2013 and ends on April 2015 and is composed by a total of 72 days of precipitation. A threshold for the environmental temperature at $2^{\circ} \mathrm{C}$ has been adopted to avoid the occurrence of liquid precipitation (Colli et a., 2015) resulting in a dataset of 183 solid precipitation data.

The 30-min WMO SPICE measurements of the shielded gauges and ancillary sensors obtained at CARE (Canada) and

25 Haukeliseter (Norway) have been processed as well. At the CARE field site, the wind speed and temperature measured at 2m above ground were measured by a NWS425 anemometer and HMP155 thermometer (Vaisala). At the Haukeliseter field site, wind speed measurements performed at a $10 \mathrm{~m}$ level above the ground have been performed by a WindObserver II anemometer manufactured by Gill Instruments and environmental temperature is measured by a PT100 platinum resistance thermometer sensor. In order to study the CE trend as a function of the wind speed, we adopted the Kochendorfer et al.

30 (2017a) approach that estimates the wind speed at the gauge height equal to $U_{10 m} \times 0.71$ by assuming a 109 wind vertical profile (Thom, 1975).

Because the snowfall type, particle size distribution and terminal velocity at a given location highly vary in time, shorter time periods were also tested. These are 1-min, 5-min, 10-min and 20-min time interval. The Meteorological Services (Matrosov et al.,2009; Gergely and Garrett, 2016) usually use 30-min or 60-min intervals. To investigate the influence of the 
Hydrol. Earth Syst. Sci. Discuss., https://doi.org/10.5194/hess-2018-447

Manuscript under review for journal Hydrol. Earth Syst. Sci.

Discussion started: 12 November 2018

sampling interval on the $C E$ variation with wind speed, the 1-min datasets at the Marshall test site from January 2013 to April 2015 was aggregated to obtained the 5-min, 10-min and 20-min time intervals. The environmental temperature of -2C was used as well to account for solid precipitation only. The wind speed and temperature datasets were also averaged over the same time intervals. A lower snowfall rate measured by the DFIR was set to $S I_{D F I R}<0.5 \mathrm{~mm} / \mathrm{h}$ to avoid cases of light

5 snow occurring at some of the sites. Under these conditions, the total dataset is composed of 29 precipitation events for a total of 6943 minutes of precipitation.

Finally, the field data are compared to CFD simulations performed by imposing the same wind speed and precipitation intensity conditions. This provides an independent confirmation of the conclusions obtained from the field measurements analysis.

\section{$10 \quad 2.2$ CFD simulation framework}

\subsubsection{Airflow modelling}

The flow field is generated basing on the airflow dataset computed and described by Colli et al. (2015) to solve the three dimensional equations for the airflow around the single Alter GEONOR T200B gauge system. The spatial domain of the shielded gauge was subdivided into 10.0 million hexahedral and polyhedral cells with different degrees of refinements close

15 to the gauge/shield surface to reach numerical convergence. The time-averaged air velocity, turbulent kinetic energy and pressure fields were solved by means of a Reynolds Averaged Navier-Stokes k- $\omega$ SST model. A direct comparison between the single Alter shielded and an unshielded configurations (Figure 3 of Colli et al., 2015) confirmed the advantage of using a single Alter shield. This gauge-shield configuration reduces the velocity magnitude in the region contained within the fence and hence the exposure of the gauge to the wind.

20 Note that the calculation assumes uniform and steady air velocity profiles upstream of the gauge. The role of boundary layer turbulence on CE is currently being analysed with more accurate time-dependent models, such as Large Eddy Simulation, and preliminary results have been presented in Colli et al. (2016b).

\subsubsection{Collection efficiency modelling}

25 The trajectories of dry and wet snow particles in the flow field past the single Alter and unshielded GEONOR gauge using wet and dry particle definitions in Rasmussen et al. (2001) were computed for wind speeds between 1 and $8 \mathrm{~m} / \mathrm{s}$ with a Lagrangian model (Colli et al. 2015).

The influence of the particle size distribution on the $C E$ scattering was analysed by simulating several particle sizes. The particle size distribution of solid precipitation can be described using the gamma distribution as shown by Brandes et al.

30 (2006): 
Hydrol. Earth Syst. Sci. Discuss., https://doi.org/10.5194/hess-2018-447

Manuscript under review for journal Hydrol. Earth Syst. Sci.

Discussion started: 12 November 2018

(c) Author(s) 2018. CC BY 4.0 License.

(c) (i)
Hydrology and

Earth System

Sciences

Discussions

$$
N(D)=N_{0} \cdot D^{\mu} \cdot D^{-\lambda \cdot D}
$$

where $N_{0}$ is the scale parameter, $\mu$ characterizes the curvature and $\lambda$ the slope of the distribution. According to Brandes et al. (2006) $\mu$ can be estimated by the following expression: $\mu=-0.00499 \lambda^{2}+0.798 \lambda-0.666$. In this work we adopted a general intercept value equal to $N_{0}=1.510^{6} \mathrm{~mm}^{-1} \mathrm{~m}^{-3}$ and a variable slope parameter between $0.5 \mathrm{~mm}^{-1}<\lambda<1.5 \mathrm{~mm}^{-1}$ (Brandes et

5 al.,2006; Theriault et al.,2012). The estimation of $C E$ is based on the particle counting technique described in Colli et al. (2016b), which adopts the following integral expression:

$$
C E\left(U_{w}\right)=\frac{\int_{0}^{d_{\text {pmax }}} V_{w}\left(d_{p}\right) A_{\text {inside }}\left(d_{p}, U_{w}\right) N\left(d_{p}\right) d_{p}}{\int_{0}^{d_{\text {pmax }}} V_{w}\left(d_{p}\right) A_{\text {gauge }} N\left(d_{p}\right) d_{p}}
$$

where $A_{\text {inside }}\left(d_{p}, U_{w}\right)$ is the effective collecting area associated with the number of particles collected by the gauge and $A_{\text {gauge }}\left(d p, U_{w}\right)$ is the area associated with the entering particles in case of undisturbed airflow and $V_{w}\left(d_{p}\right)$ the equivalent water volume.

\section{Results from the field data analysis}

The empirical CE for the single Alter shielded gauge as a function of wind speed, when the snow accumulation is aggregated over a 30 min time interval, is shown in Figure 1. The two panels show the same $C E$ data calculated from field measurements but colour coded according to the air temperature $T$ (panel a) and to the snowfall intensity $S I_{S A}$, as measured by the single Alter shielded gauge (panel b). The clustering of the $C E$ according to the $S I_{S A}$ is evident. It is observed that, for a given wind speed $U_{w}$, different $C E=P_{S A} / P_{D F I R}$ ratios may occur according to a specific $S I_{S A}$, with higher collection efficiency values observed when the gauge collects an higher snowfall intensity. This trend becomes more evident when the mean horizontal wind speed is higher than $2 \mathrm{~m} / \mathrm{s}$ with a more relevant clustering of the data according to $S I_{S A}$. 
Hydrol. Earth Syst. Sci. Discuss., https://doi.org/10.5194/hess-2018-447

Manuscript under review for journal Hydrol. Earth Syst. Sci.

Discussion started: 12 November 2018
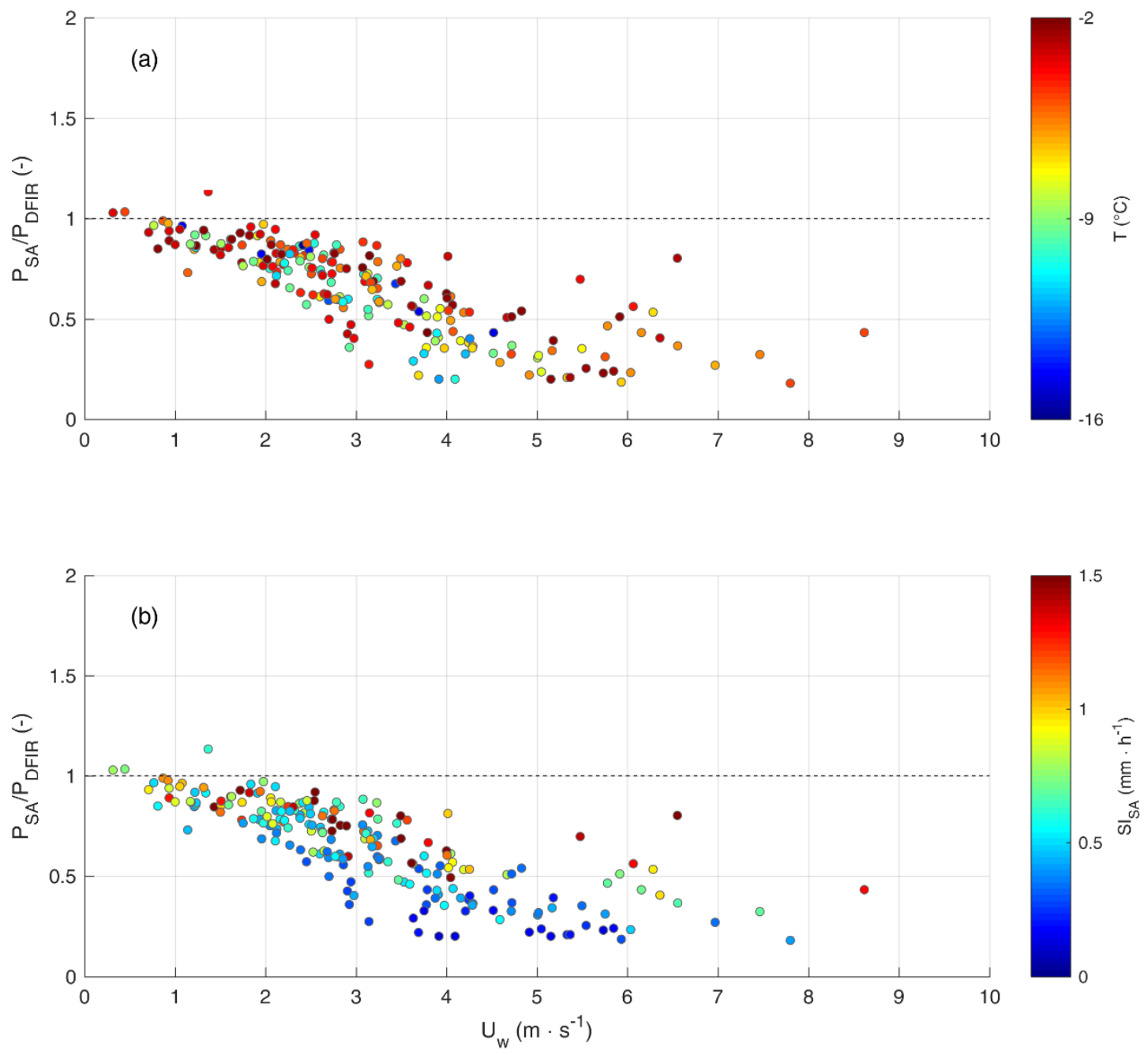

Figure 1: Collection efficiency $C E=P_{S A} / P_{D F I R}$ for the $30 \mathrm{~min}$ single Alter gauge measurements from the Marshall field site in the period October 2013 to April 2015. Data points are colour coded according to the air temperature $T$ (panel a) and the measured snowfall intensity $S I_{S A}$ (panel b) showing the clustering of the measurements.

One explanation of the larger $C E$ yielded by higher $S I_{S A}$ of this trend is that the particles sizes are larger for higher snowfall intensities and, hence, less prone to be deflected by the deformed airflow above the gauge collector (Colli et al. 2016a,b). Thériault et al. $(2012,2015)$ and Colli et al. (2015) showed a correlation between the slope parameter of the particle size distribution observed outside the tested gauge and its collection efficiency. Since low values of the slope mean larger particle sizes, this is consistent with the above suggestion. 
Hydrol. Earth Syst. Sci. Discuss., https://doi.org/10.5194/hess-2018-447

Manuscript under review for journal Hydrol. Earth Syst. Sci.

Discussion started: 12 November 2018

(c) Author(s) 2018. CC BY 4.0 License.
Hydrology and

Earth System

Sciences

Discussions

(c) (i)

In the following, the collection efficiency analysis is focused on the SPICE quality controlled 30 min dataset as used by Kochendorfer et al. (2017). A least squares regression of the inverse exponential function of $C E\left(U_{w}, S I_{S A}\right)$ presented in equation 3 has been performed for the single Alter shielded gauge basing on the Marshall field site dataset together with the best fit obtained by equation 1 where the collection efficiency is expressed as a function of $U_{w}$ and $T$. The coefficients obtained by the best-fit analysis are listed in Table 1 .

Table 1: CE inverse exponential function coefficients $(a, b$ and $c$ ), number of periods available $(n)$ and linear correlation coefficient (r) for 30 min measurements made by the single Alter gauge at the Marshall (USA), CARE (Canada) and Haukeliseter (Norway) field sites from October 2013 to April 2015. The regression coefficients are calculated and compared for both $C E\left(U_{w}, S I_{S A}\right)$ and $C E\left(U_{w}, T\right)$ at each field site.

\begin{tabular}{c|c|ccc|c|c} 
Field site & $\boldsymbol{C E}$ formulation & $\boldsymbol{a}$ & $\boldsymbol{b}$ & $\boldsymbol{c}$ & $\boldsymbol{n}$ & $\boldsymbol{r}$ \\
\hline Marshall (USA) & $C E\left(U_{w}, S I_{S A}\right)$ & 0.6737 & 12.8976 & 0.6589 & 183 & 0.91 \\
& $C E\left(U_{w}, T\right)$ & 0.0520 & 0.1874 & 1.4971 & 183 & 0.82 \\
CARE (Canada) & $C E\left(U_{w}, S I_{S A}\right)$ & 3.4531 & 107.4708 & 0.5835 & 234 & 0.85 \\
& $C E\left(U_{w}, T\right)$ & 0.2892 & 0.0126 & -0.7551 & 234 & 0.75 \\
Haukeliseter (Norway) & $C E\left(U_{w}, S I_{S A}\right)$ & 0.4217 & 7.6856 & 0.7372 & 485 & 0.87 \\
& $C E\left(U_{w}, T\right)$ & 0.5650 & 0.0198 & -0.6711 & 485 & 0.75
\end{tabular}

The two regressions are presented in Figure 2. These are the $C E\left(U_{w}, S I_{S A}\right)$ (panel a) and $C E\left(U_{w}, T\right)$ (panel b) surfaces together with the field measurements (red points). The CE surfaces are colored according to the collection efficiency value and the

$15 C E\left(U_{w}, S I_{S A}\right)$ regression (panel b) shows a relevant dependency on the measured snowfall intensity together with the wind speed. Having selected a solid precipitation dataset according to the $\mathrm{T}<-2^{\circ} \mathrm{C}$ threshold, the $C E\left(U_{w}, T\right)$ regression represented in panel a shows a weak dependency to the environmental temperature $T$. 
Hydrol. Earth Syst. Sci. Discuss., https://doi.org/10.5194/hess-2018-447

Manuscript under review for journal Hydrol. Earth Syst. Sci.

Discussion started: 12 November 2018

(c) Author(s) 2018. CC BY 4.0 License.

(c) $\underset{\mathrm{BY}}{\mathrm{B}}$
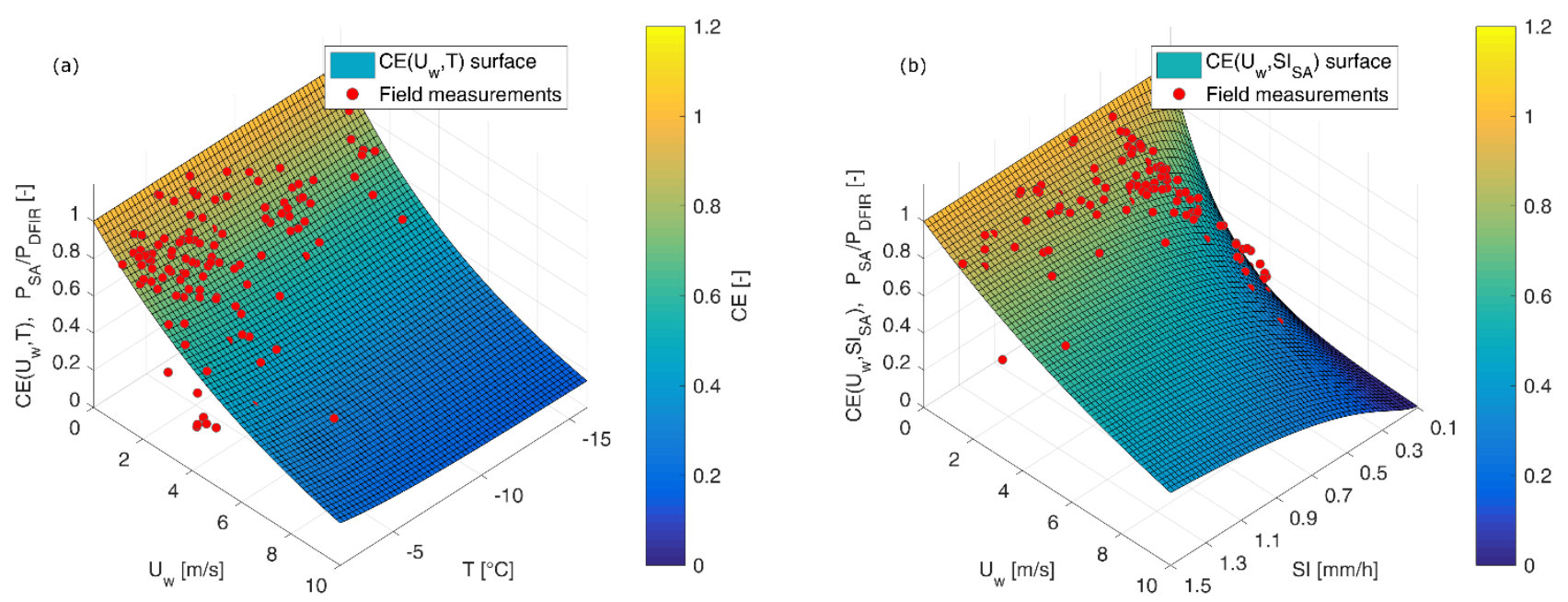

Figure 2: Collection efficiency $C E=P_{S A} / P_{D F I R}$ of the 30-min single Alter gauge measurements made at the Marshall field site (red dots) and best-fit surfaces. Two regressions have been performed by expressing $\mathrm{CE}$ as a function of the wind speed $U_{w}$ and either the air temperature $\mathrm{T}$ (panel a) or the measured snowfall intensity $S I_{S A}$ (panel b).

5 In order to highlight the observed dependency between the $C E$ and the snowfall intensity measured by the uncorrected gauge, Figure 3 presents $C E\left(U_{w}, S I_{S A}\right)$ plots for smaller subsets of field data selected according to the SI class. A non-gradient multi-objective genetic optimization algorithm, implemented in the DAKOTA open source toolkit (Eldred et al., 2007), was used to retrieve the best SI class limits (namely $0.0<S I_{S A}<=0.4 \mathrm{~mm} \mathrm{~h}^{-1}, 0.4<S I_{S A}<=0.6 \mathrm{~mm} \mathrm{~h}^{-1}, 0.6<S I_{S A}<=1.0 \mathrm{~mm} \mathrm{~h}^{-1}$ and $\left.1.0<S I_{S A}<=1.5 \mathrm{~mm} \mathrm{~h}^{-1}\right)$. The optimization objectives were to maintain a significant sample size for each bin and to minimize

10 the scatter of the $\mathrm{CE}$ values around their best fit curves (represented by the standard deviation of the residuals). The results show that each intensity category has a different fit to the sigmoid, with the lowest rates having the steepest decrease in collection efficiency with wind speed. This result is consistent with the highest intensities having the largest particles and therefore the smallest collection efficiency drops with wind speed. 
Hydrol. Earth Syst. Sci. Discuss., https://doi.org/10.5194/hess-2018-447

Manuscript under review for journal Hydrol. Earth Syst. Sci.

Discussion started: 12 November 2018
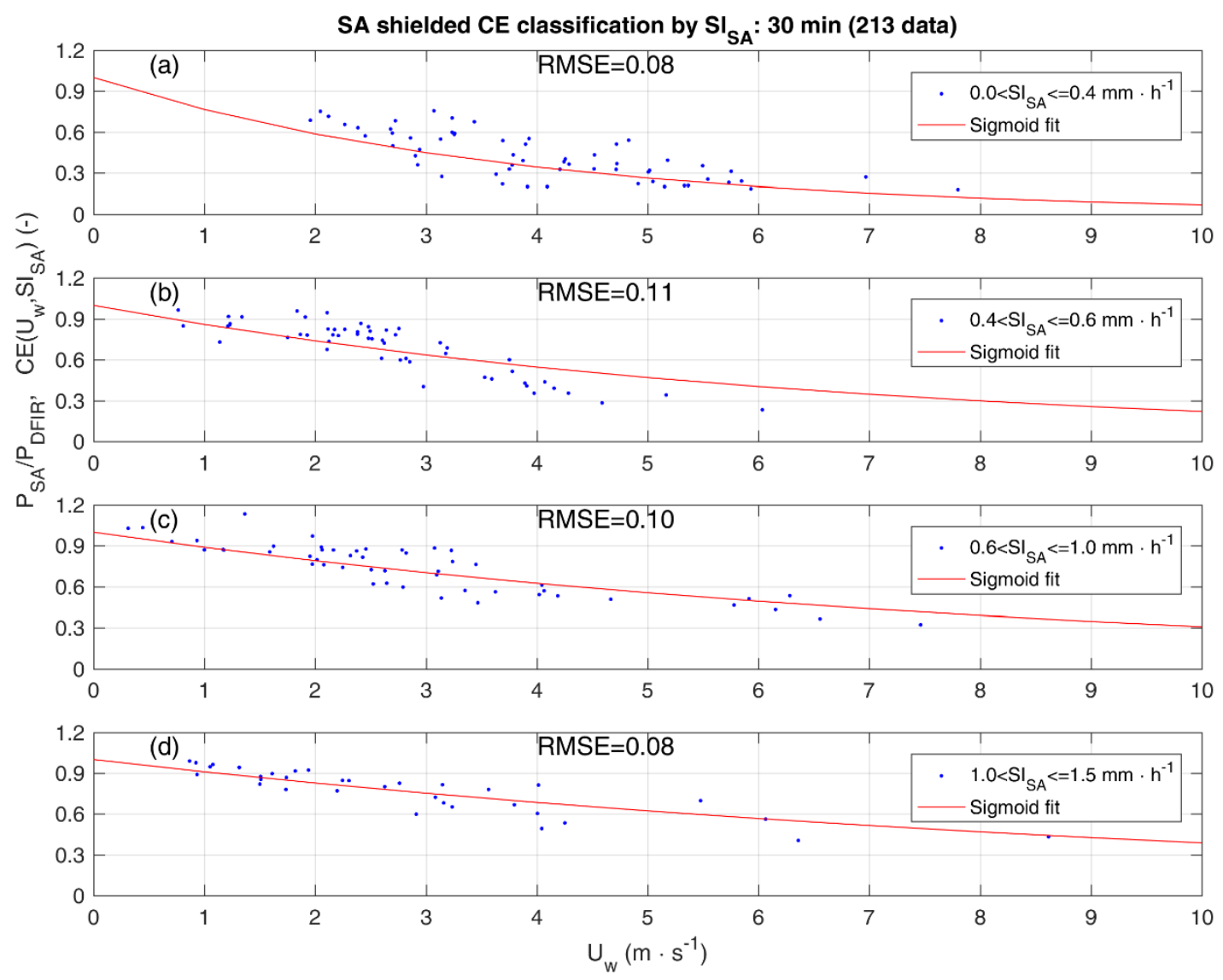

Figure 3: Empirical $C E=P_{S A} / P_{D F I R}$ from measurements made by the single Alter snow gauge at the Marshall field site as a function of wind speed with a 30-min sampling interval. The solid line in each panel is the sigmoid best fit to the data. Each panel represents a different range of snow intensity $\left(S I_{S A}\right)$ as indicated by the key in the upper right of each panel and contains an evaluation of the RMSE of the residuals.

Wolff et al. (2015) and Colli et al. (2016b) showed that the influence of the type of precipitation on the catch performance of precipitation gauges could be taken into account by specifying the $C E$ values according to the air temperature when considering the transition from snow to rain. The air temperature is an efficient indicator to recognize rainfall $\left(T>2{ }^{\circ} \mathrm{C}\right)$ from wet snow $\left(-2^{\circ} \mathrm{C}<T<+2^{\circ} \mathrm{C}\right)$ and dry snow $\left(T<-2^{\circ} \mathrm{C}\right)$ cases but it is not representative of the large variety of dry snow crystal types neither the rimed snow (Rasmussen et al., 1999 and Thériault et al., 2012). Figure 4 shows clearly that the scatter in the data is better represented by the $S I$ rather than the air temperature. The four $C E\left(U_{w}, T\right)$ curves show similar trends and nearly overlap each other demonstrating that there is no significant correlation between the dry snow wind-induced undercatch and temperature below $-2^{\circ} \mathrm{C}$. In contrast, the curves show a distinct separation when categorized by snowfall intensity for the

15 30-min dataset (Fig. 4, solid lines). 
Hydrol. Earth Syst. Sci. Discuss., https://doi.org/10.5194/hess-2018-447

Manuscript under review for journal Hydrol. Earth Syst. Sci.

Discussion started: 12 November 2018

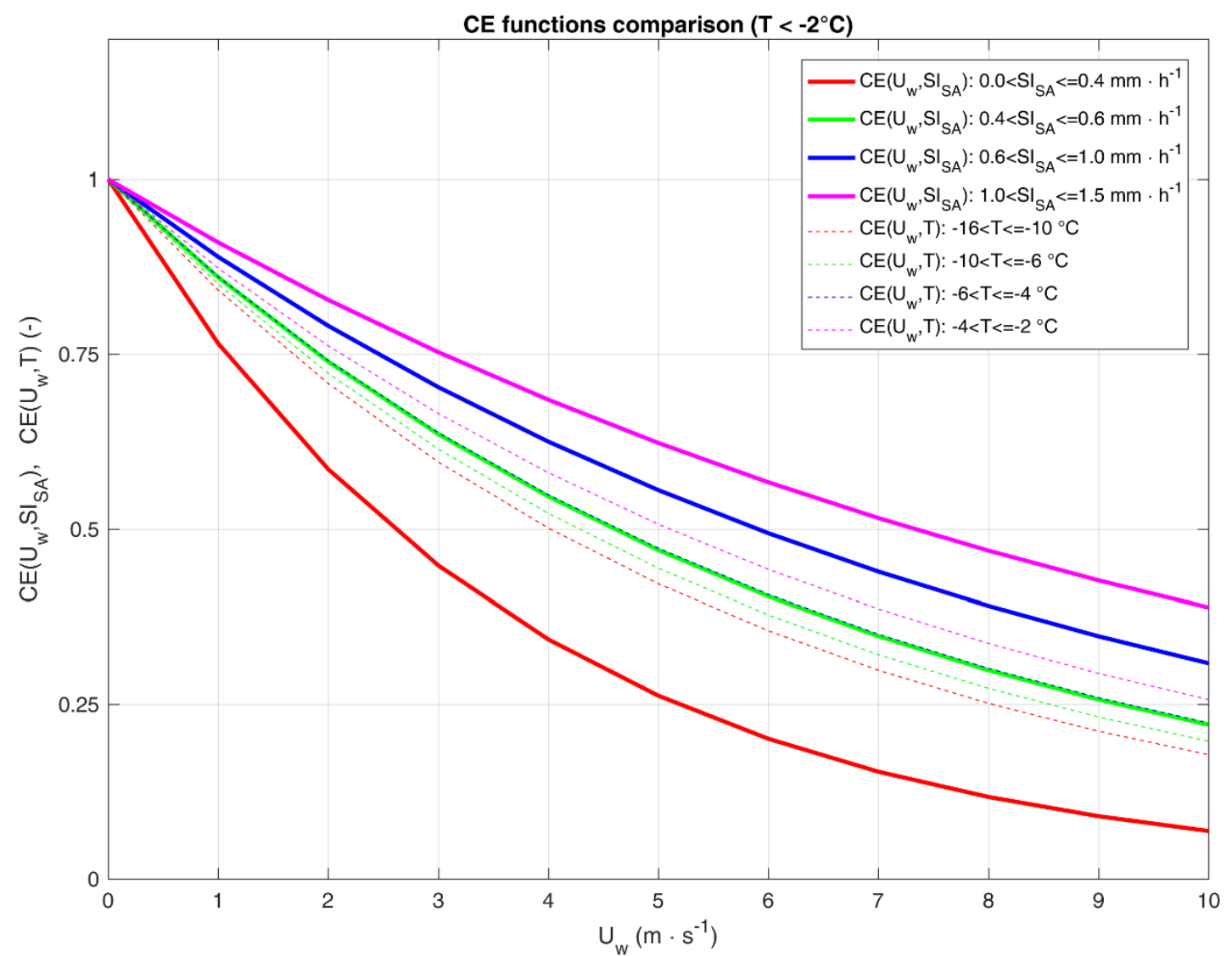

Figure 4: $C E\left(U_{w}\right)$ curves of the measurements made by the single Alter snow gauge at the Marshall field site grouped by the environmental temperature $T$ (dashed lines) and the measured snowfall intensity $S_{S A}$ (solid lines) with a 30-min accumulation time.

5 An evaluation of the improvement to the snowfall accumulation estimates when using the intensity dependent curve fit is shown in Figure 5a, which represents the corrected $C E$ and the associated root mean square error (RMSE). The field data fall about a $C E$ of 1.0 and the residual scattering is quantified by a $R M S E$ equal to 0.10 . The colour coded distribution of the environmental temperature on the corrected $C E$ appears quite random. A larger scatter $(R M S E=0.14)$ is observed when the measurements are corrected by using wind speed and temperature (Fig. 5b, traditional approach). 
Hydrol. Earth Syst. Sci. Discuss., https://doi.org/10.5194/hess-2018-447

Manuscript under review for journal Hydrol. Earth Syst. Sci.

Discussion started: 12 November 2018
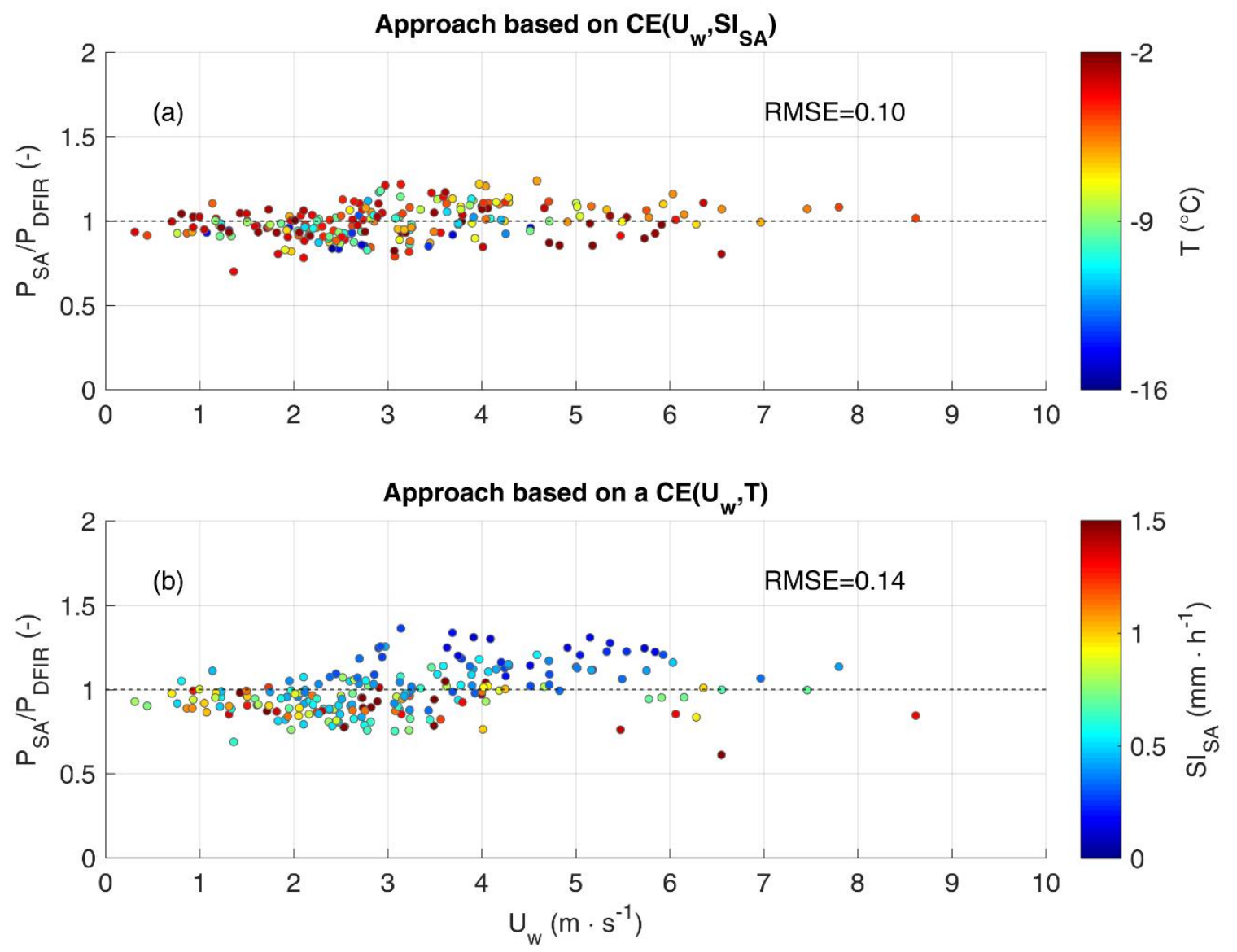

Figure 5: Residuals of $C E=P_{S A} / P_{D F I R}$ after correcting the $30 \mathrm{~min}$ single Alter snow gauge measurements from the Marshall field site using Equation 3 (top panel) and Equation 1 (bottom panel), with the associated RMSE values. Residuals are colour coded according to the environmental temperature $T$ (top panel) and the snowfall intensity $S I_{S A}$ (bottom panel).

Note that Figure 5b shows a colour separated dependence on wind speed, indicating that the $C E\left(U_{w}, T\right)$ approach does not exploit all the forms of dependency between the accumulated precipitation measured by the single Alter shielded gauge and the characteristics of the precipitation events.

The best fit coefficient of the collection efficiency regression obtained with the CARE and Haukeliseter datasets are reported

10 in Table 1 for both the $C E\left(U_{w}, T\right)$ and $C E\left(U_{w}, S I_{S A}\right)$ formulations. The correction of the measurements based on such transfer functions is shown on Figure 6 and 7. The RMSEs of the residuals for the CARE measurements are equal to 0.09 in the case of $C E\left(U_{w}, S I_{S A}\right)$ and 0.12 in the case of $C E\left(U_{w}, T\right)$ while the residuals for the Haukeliseter measurements show RMSEs that are equal respectively to 0.16 and 0.22 . These RMSE results confirm that a correction based on the wind speed and precipitation intensity leads to a higher precision of the solid precipitation measurements compared to when only the wind

15 speed and environmental temperature are used. 
Hydrol. Earth Syst. Sci. Discuss., https://doi.org/10.5194/hess-2018-447

Manuscript under review for journal Hydrol. Earth Syst. Sci.

Discussion started: 12 November 2018
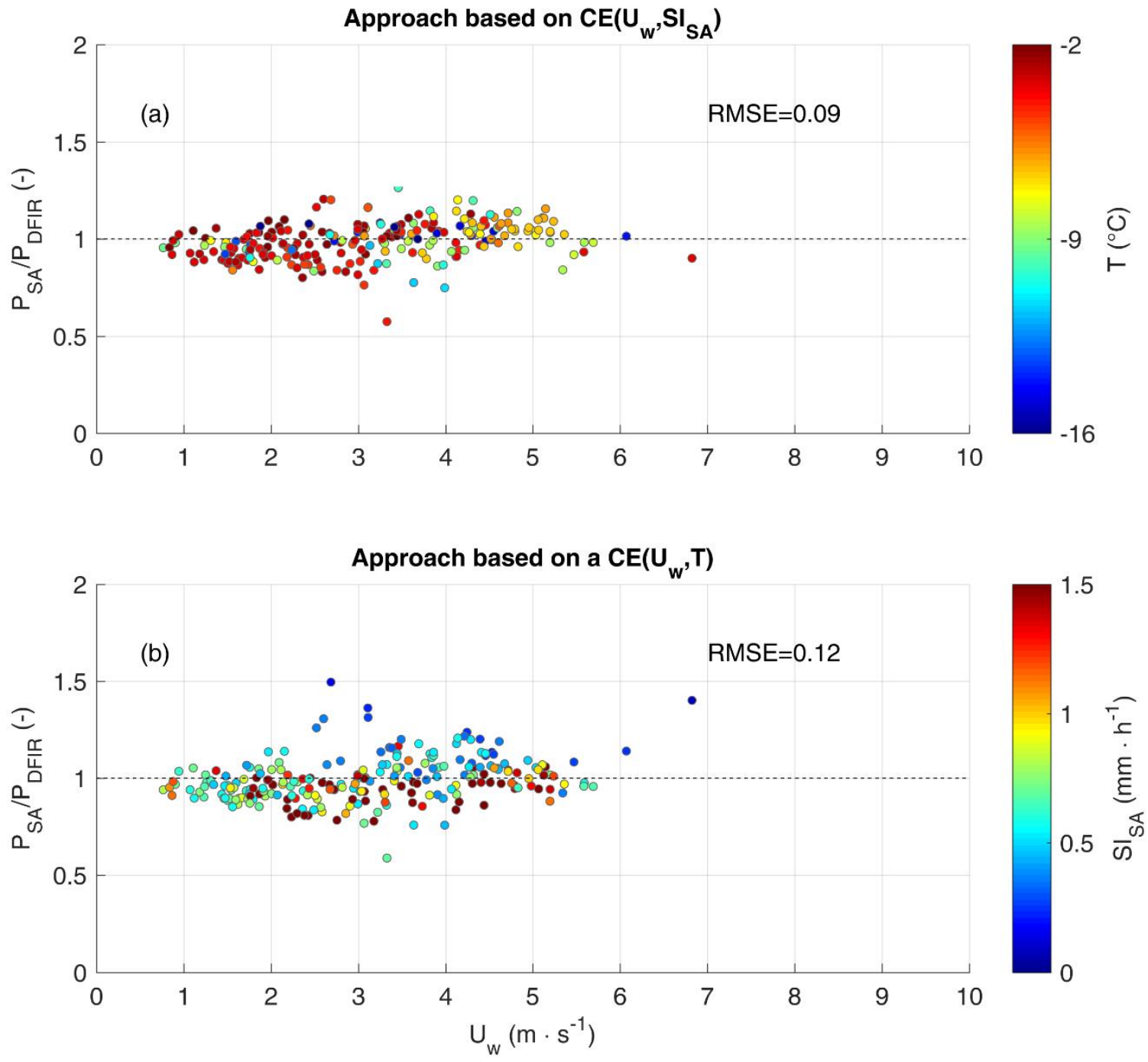

Figure 6: Residuals of $C E=P_{S A} / P_{D F I R}$ after correcting the 30 min single Alter snow gauge measurements from the CARE (Canada) field site using Equation 3 (top panel) and Equation 1 (bottom panel), with the associated RMSE values. Residuals are colour coded according to the environmental temperature $\mathrm{T}$ (top panel) and the snowfall intensity $S I_{S A}$ (bottom panel). 
Hydrol. Earth Syst. Sci. Discuss., https://doi.org/10.5194/hess-2018-447

Manuscript under review for journal Hydrol. Earth Syst. Sci.

Discussion started: 12 November 2018
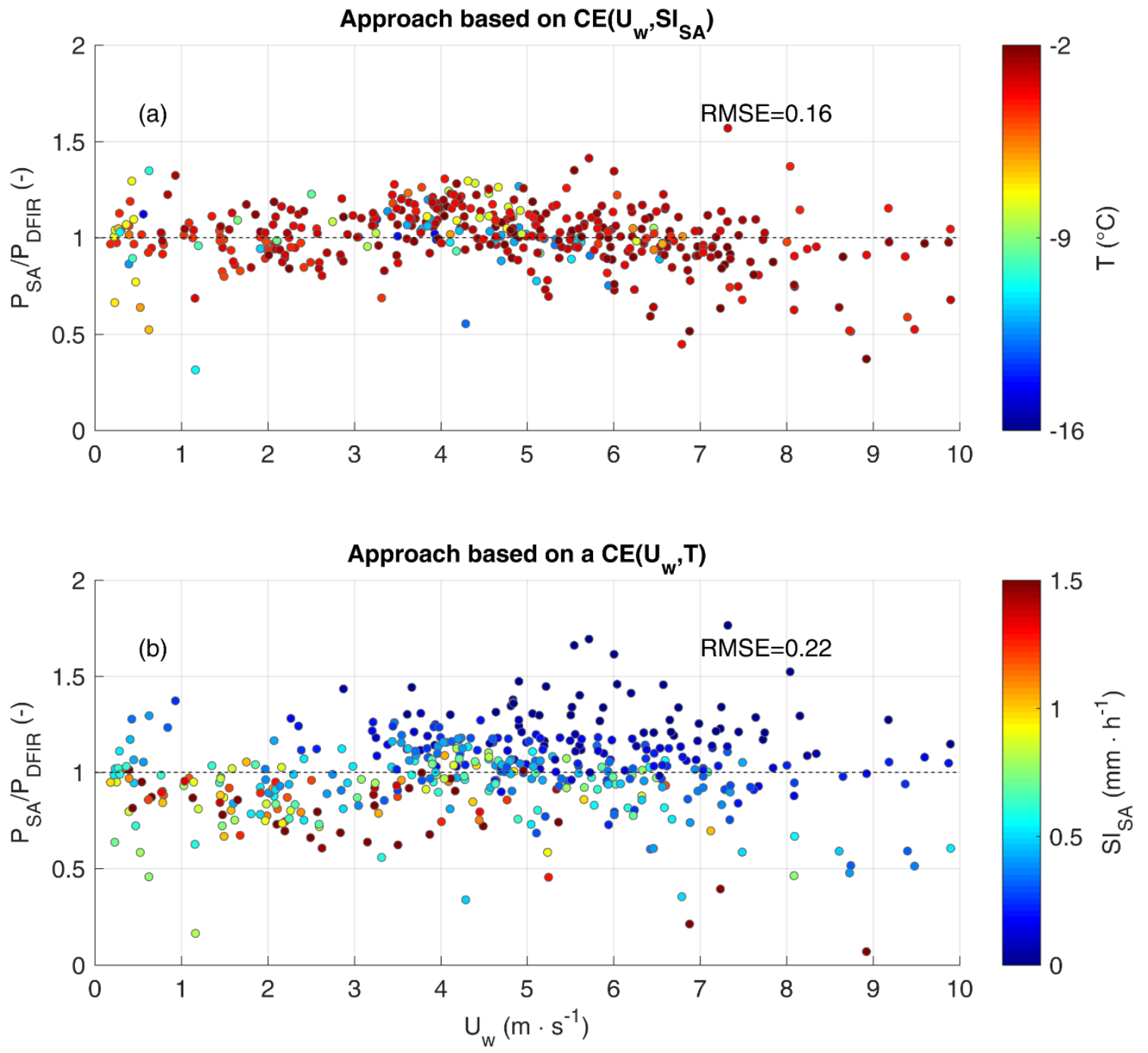

Figure 7: Residuals of $C E=P_{S A} / P_{D F I R}$ after correcting the $30 \mathrm{~min}$ single Alter snow gauge measurements from the Haukeliseter (Norway) field site using Equation 3 (top panel) and Equation 1 (bottom panel), with the associated RMSE values. Residuals are colour coded according to the environmental temperature T (top panel) and the snowfall intensity $S_{S A}$ (bottom panel). 
Hydrol. Earth Syst. Sci. Discuss., https://doi.org/10.5194/hess-2018-447

Manuscript under review for journal Hydrol. Earth Syst. Sci.

Discussion started: 12 November 2018

\section{Sensitivity to the time aggregation}

The analysis of field data proposed in section 3 has been repeated on 1-min measurements performed by the single Alter gauge at the Marshall field site from January 2013 to April 2015 and aggregated over time intervals equal to 5, 10, 30 and 60 min. The regression coefficients obtained by applying the inverse exponential laws described by equations 1 and 3 are

5 reported in Table 2. Figure 8 shows $C E$ specified for different measured snowfall intensities $S I_{S A}$ and time resolutions $\Delta t$. In all cases, a strong $C E$ dependency on $S I_{S A}$ draws distinct variations with wind speed, which do not overlap with each other. On the other hand, measurements made with a 30-min sampling interval provide CE curves that are closer to each other, and hence slightly less influenced by the measured snowfall intensity, but still significantly different. This is partially explained by the fact that $S I_{S A}$ is strongly time dependent and when the intensity measurements are averaged over a large time interval

10 they become less representative of the internal variability.

The representativeness of the proposed $C E\left(U_{w}, T\right)$ transfer functions (represented by their linear correlation coefficient $r$ in Table 2) with respect to the field measurements decreases sharply below 5 minutes for temperature, while it doesn't for $C E\left(U_{w}, S I_{S A}\right)$, suggesting that the $T$ dependence becomes weaker at high resolution while the $S I_{S A}$ dependence not so much. A similar behaviour is reported by Table 3 in terms of RMSE, where the transition between the 5-min and the 1-min

15 aggregation intervals yields the larger $R M S E$ increase for the $C E\left(U_{w}, T\right)$ formulation. Therefore, the $S I_{S A}$ dependence is more robust with respect to time aggregation. As shown in section 3, SPICE used a 30-min period to assess CE, which still show significant variability at a given wind speed.

Table 2: Coefficients $(a, b$ and $c)$ of the inverse exponential function fitted at various aggregation intervals for the $C E\left(U_{w}, T\right)$ and $C E\left(U_{w}, S I_{S A}\right)$ formulations, linear correlation coefficient $(r)$, and number of periods available $(n)$. The calculation used measurements made by single Alter gauge at the Marshall field site from January 2013 to April 2015.

\begin{tabular}{|c|c|c|c|c|c|c|c|c|c|}
\hline \multirow{3}{*}{$\begin{array}{c}\Delta t \\
(\min )\end{array}$} & \multicolumn{3}{|c|}{$C E\left(U_{w}, T\right)$} & \multicolumn{4}{|c|}{$C E\left(U_{w}, S I_{S A}\right)$} & \multirow{3}{*}{$r$} & \multirow{3}{*}{$n$} \\
\hline & $a$ & $b$ & $c$ & $r$ & $\mathbf{a}$ & $b$ & $c$ & & \\
\hline & $(-)$ & $(-)$ & $(-)$ & & $(-)$ & $(-)$ & $(-)$ & & \\
\hline 1 & 0.0588 & 0.6575 & 1.0502 & 0.60 & 18.0058 & 213.0772 & 0.5717 & 0.87 & 6943 \\
\hline 5 & 0.0539 & 0.7155 & 1.1036 & 0.75 & 1.8436 & 27.9843 & 0.5957 & 0.90 & 1405 \\
\hline 10 & 0.0500 & 1.1350 & 1.1648 & 0.81 & 0.4372 & 6.5754 & 0.6851 & 0.91 & 697 \\
\hline 30 & 0.0555 & 0.9313 & 0.8761 & 0.85 & 0.3141 & 4.8702 & 0.7596 & 0.94 & 226 \\
\hline 60 & 0.0539 & 1.0996 & 0.9338 & 0.87 & 0.2985 & 4.6410 & 0.7649 & 0.95 & 115 \\
\hline
\end{tabular}


Hydrol. Earth Syst. Sci. Discuss., https://doi.org/10.5194/hess-2018-447

Manuscript under review for journal Hydrol. Earth Syst. Sci.

Discussion started: 12 November 2018

(c) Author(s) 2018. CC BY 4.0 License.
Hydrology and

Earth System

Sciences

Discussions

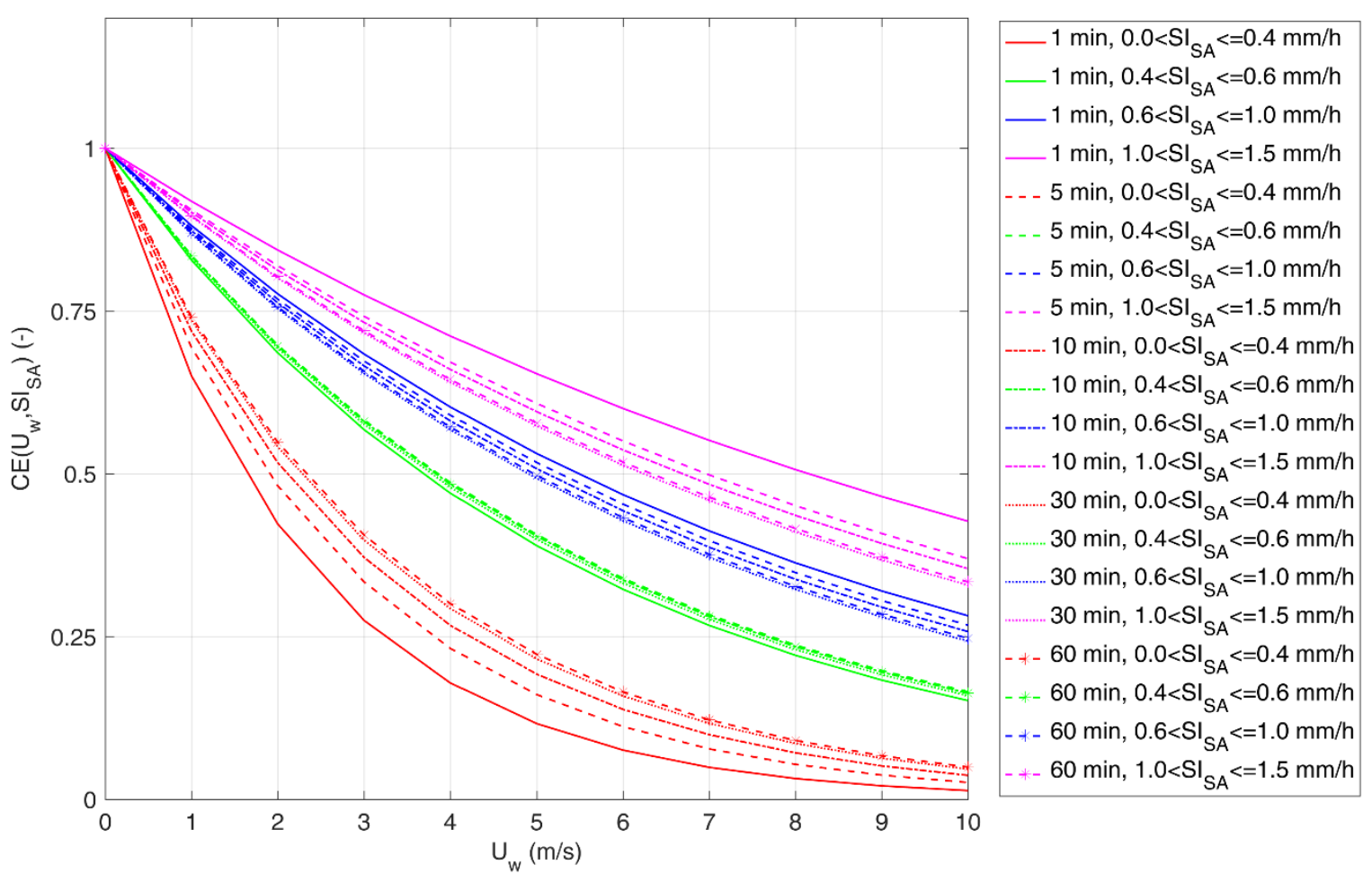

Figure 8: Collection efficiency $C E\left(U_{w}, S I\right)$ curves of the single Alter snow gauge at the Marshall field site at 1, 5, 10, 30 and 60 min sampling intervals (different line types) grouped by the measured snowfall intensity SI (different line colors).

5 Figure 8 demonstrates that the 10 min time interval may represent a trade-off point between the availability of correlated $S I_{S A}$ and $C E$ observations and the need of accumulating significant amounts of snowfall when lower precipitation intensities occur. An evaluation of the impact of the data integration time on the correction of the $\mathrm{P}_{\mathrm{SA}}$ observations was made by considering snowfall accumulations computed from different periods. Table 3 shows that a larger dispersion of the corrected wind induced measurements (quantified by the root mean squared error RMSE) around the optimal value ( $C E=1$ ) is observed

10 when smaller time periods are considered. Table 3 also shows that smaller RMSEs are systematically observed when $C E$ is calculated using the measured snowfall intensity. On the other hand, shorter time intervals show a larger improvement of the correction when using the measured snowfall intensity as demonstrated by larger values of the difference $\triangle R M S E=\operatorname{RMSE}\left(C E\left(U_{w}, T\right)\right)-\operatorname{RMSE}\left(C E\left(U_{w}, S I\right)\right)$. This is a consequence of the increasingly better fit of the $C E\left(U_{w}, S I_{S A}\right)$ formulation with reducing the aggregation scale, as already shown in Table 2. 
Hydrol. Earth Syst. Sci. Discuss., https://doi.org/10.5194/hess-2018-447

Manuscript under review for journal Hydrol. Earth Syst. Sci.

Discussion started: 12 November 2018

Table 3: Root mean square error of the solid precipitation measurements made by the single Alter gauge at the Marshall field site over different time intervals $\Delta t$ by applying a correction based on snowfall intensity, $C E\left(U_{w}, S I_{S A}\right)$, and air temperature, $C E\left(U_{w}, T\right)$, and their difference $\triangle R M S E$.

\begin{tabular}{c|ccc}
$\Delta t$ & $\boldsymbol{R M S E}\left(\boldsymbol{C E}\left(\boldsymbol{U}_{w}, \boldsymbol{T}\right)\right)$ & $\mathrm{RMSE}\left(\boldsymbol{C E}\left(\boldsymbol{U}_{w}, \boldsymbol{S} I_{S A}\right)\right)$ & $\Delta R M S E$ \\
$(\mathbf{m i n})$ & $(-)$ & $(-)$ & $(-)$ \\
\hline 1 & 0.26 & 0.16 & 0.10 \\
5 & 0.19 & 0.12 & 0.07 \\
10 & 0.16 & 0.11 & 0.05 \\
30 & 0.13 & 0.08 & 0.04 \\
60 & 0.12 & 0.07 & 0.05
\end{tabular}

5 The fact that the amount of scatter reduction $\triangle R M S E$ increases with shorter accumulation time intervals, seems to support the need of high-resolution measurements to improve the accuracy of the snow data. For instance, the scatter resulting from the correction of 30-min accumulation measurements based on wind speed and temperature can be achieved for a 10-min accumulation measurements if the snowfall intensity is used for the correction. Thus, one can either achieve higher skills for a given time period of accumulation or achieve a higher time resolution with RSE similar to the one traditionally obtained for a longer time period by including the snowfall intensity in the transfer function.

\section{CFD Validation}

\subsection{PSD and snowfall intensity collected by the gauge}

The CFD analysis performed by Thériault et al. (2012) found a physical explanation for the large variability of the gauge

15 catch performance observed for a given $U_{w}$ and a specific type of precipitation from variations in the particle size distribution. Colli et al. (2015) confirmed this conclusion by providing different $C E\left(U_{w}\right)$ functions computed using an improved CFD approach corresponding to the slope parameter $(\lambda)$ equal to $0.25,0.50$ and $1 \mathrm{~mm}^{-1}$ (the same values used by Thériault et al. 2012).

We expanded that work here and the collection efficiency results for a larger set of $\lambda s$ and reference snowfall intensity values are reported in Table 4. The table shows that steeper PSD slopes (represented by higher $\lambda$ ), and as a consequence smaller mean particle sizes, are characterized by lower values of CE. This is due to the stronger influence of the airflow around the gauge collector on the trajectories of the smaller particles. The $C E$ values calculated in Table 4 shows that the variability of $C E$ for a given $\lambda$ remains significant in all the simulations performed with a wind speed higher than $3 \mathrm{~m} \mathrm{~s}^{-1}$. 
Hydrol. Earth Syst. Sci. Discuss., https://doi.org/10.5194/hess-2018-447

Manuscript under review for journal Hydrol. Earth Syst. Sci.

Discussion started: 12 November 2018

Table 4: Ratio between the collected snowfall intensity and the reference snowfall intensity $S I\left(\mathrm{mmh}^{-1}\right)$ by varying the wind speed $U_{w}\left(\mathrm{~m} \mathrm{~s}^{-1}\right)$ and the slope parameter $\lambda\left(\mathrm{mm}^{-1}\right)$ of the particle size distribution.

\begin{tabular}{l|llllllll}
$\boldsymbol{\lambda}$ & $\mathbf{0 . 5}$ & $\mathbf{0 . 7}$ & $\mathbf{0 . 9}$ & $\mathbf{1 . 1}$ & $\mathbf{1 . 3}$ & $\mathbf{1 . 5}$ & $\mathbf{1 . 7}$ & $\mathbf{1 . 9}$ \\
$\mathbf{S I}$ & $\mathbf{8 . 4 9}$ & $\mathbf{3 . 8 6}$ & $\mathbf{2 . 1}$ & $\mathbf{1 . 2 6}$ & $\mathbf{0 . 8 1}$ & $\mathbf{0 . 5 4}$ & $\mathbf{0 . 3 8}$ & $\mathbf{0 . 2 7}$ \\
\hline $\mathrm{U}_{\mathrm{w}}=1 \mathrm{~m} / \mathrm{s}$ & 1 & 1 & 1 & 1 & 1 & 1 & 1 & 1 \\
$\mathrm{U}_{\mathrm{w}}=2 \mathrm{~m} / \mathrm{s}$ & 0.97 & 0.97 & 0.97 & 0.97 & 0.97 & 0.97 & 0.97 & 0.97 \\
$\mathrm{U}_{\mathrm{w}}=3 \mathrm{~m} / \mathrm{s}$ & 0.94 & 0.93 & 0.93 & 0.93 & 0.93 & 0.93 & 0.93 & 0.92 \\
$\mathrm{U}_{\mathrm{w}}=4 \mathrm{~m} / \mathrm{s}$ & 0.87 & 0.86 & 0.85 & 0.84 & 0.84 & 0.83 & 0.82 & 0.81 \\
$\mathrm{U}_{\mathrm{w}}=5 \mathrm{~m} / \mathrm{s}$ & 0.78 & 0.74 & 0.7 & 0.67 & 0.63 & 0.6 & 0.57 & 0.54 \\
$\mathrm{U}_{\mathrm{w}}=6 \mathrm{~m} / \mathrm{s}$ & 0.69 & 0.61 & 0.54 & 0.47 & 0.41 & 0.35 & 0.31 & 0.27 \\
$\mathrm{U}_{\mathrm{w}}=7 \mathrm{~m} / \mathrm{s}$ & 0.51 & 0.39 & 0.29 & 0.21 & 0.15 & 0.11 & 0.08 & 0.06 \\
$\mathrm{U}_{\mathrm{w}}=8 \mathrm{~m} / \mathrm{s}$ & 0.32 & 0.19 & 0.11 & 0.06 & 0.03 & 0.02 & 0.01 & 0.01
\end{tabular}

The simulated size distribution of particles that fall into the gauge is shown in Figure 9 for a sample precipitation characterized by $\lambda=1.0 \mathrm{~mm}^{-1}$ and $N_{0}=10^{\wedge} 6 \mathrm{~mm}^{-1} \mathrm{~m}^{-3}$, as suggested by Houze et al. (1979) who observed the snow size distribution in different atmospheric conditions. The gauge starts missing the lower particle sizes when $U_{w}$ approaches $4 \mathrm{~m} \mathrm{~s}$ ${ }^{1}$, and higher wind speeds correspond to narrower ranges of $D_{p}$ that are collected by the gauge (and higher curvature 10 parameter $\mu$ ). 
Hydrol. Earth Syst. Sci. Discuss., https://doi.org/10.5194/hess-2018-447

Manuscript under review for journal Hydrol. Earth Syst. Sci.

Discussion started: 12 November 2018

(c) Author(s) 2018. CC BY 4.0 License.

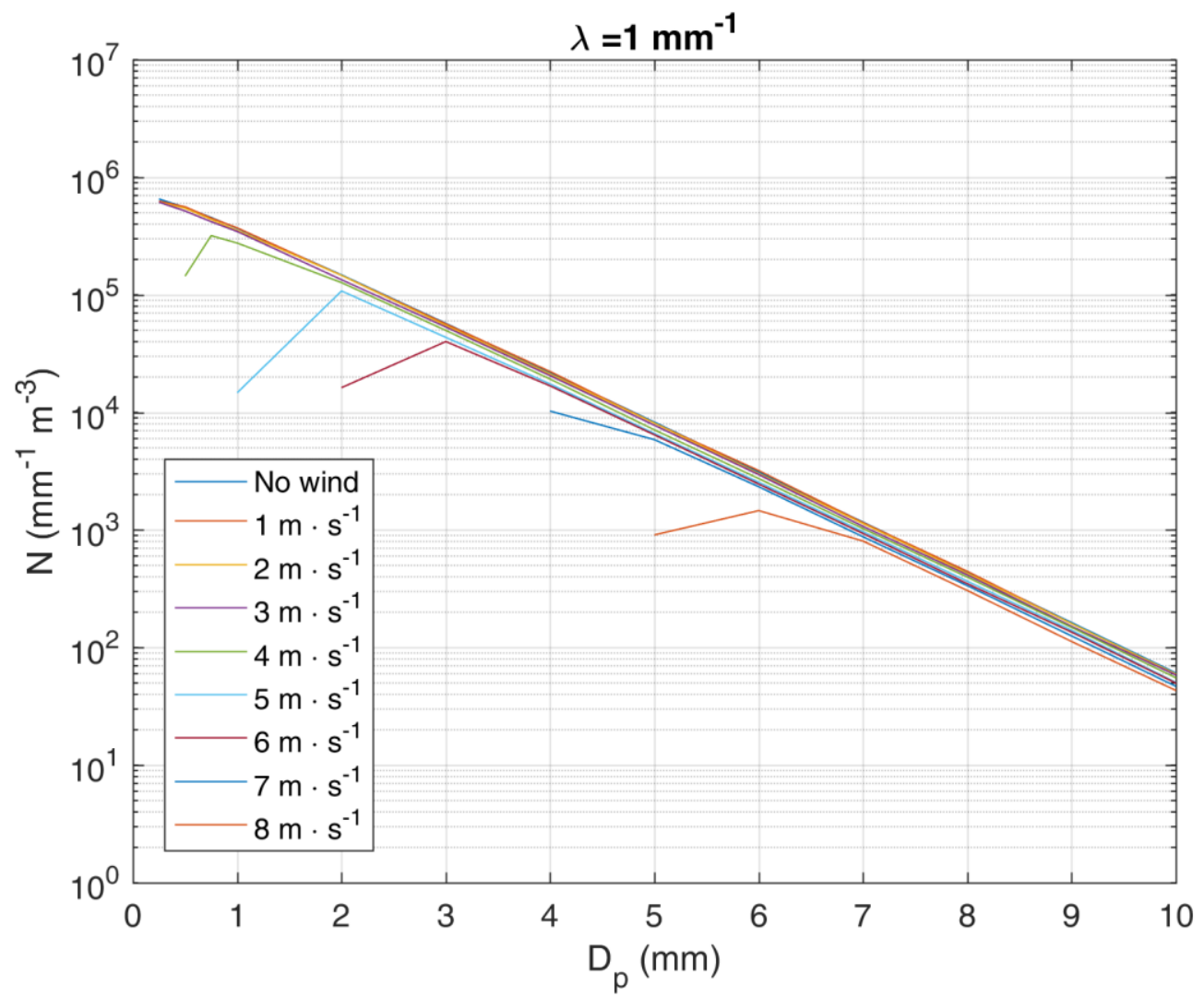

Figure 9: CFD simulated particle size distributions $N\left(D_{p}\right)$ of solid precipitation collected by the single Alter gauge under different wind conditions.

For the larger $D_{p}$, the PSD of the precipitation collected by the gauge maintains the same slope $\lambda$ of the reference and slightly decrease the concentration number $N_{0}$ with increasing $U_{w}$. The collected $N\left(D_{p}\right)$ values are lower than the reference PSD but maintain the same order of magnitude. An exception is represented by the smaller diameter of the PSDs collected under wind speeds higher than $4 \mathrm{~m} \mathrm{~s}^{-1}$. In this case, the $N\left(D_{p}\right)$ value is approximately one order of magnitude lower than the reference one.

The main consequence of the $\lambda$ invariance is that the significant wind-induced underestimation of $S I_{S A}$ reported by Table 4 is principally explained by the loss of high concentration small particles.

\subsection{Comparing the results of field observations and CFD simulations}

The computed $C E$ variation with wind speed for the different snowfall intensities is shown in Figure 10. The Marshall field site measurements are reported in Fig. 10b while the results of the CFD trajectory analysis are shown in Fig. 10a. The plot is comparable to Figure 8 of Colli et al (2015) where the correlation between the simulated collection efficiency and the 
Hydrol. Earth Syst. Sci. Discuss., https://doi.org/10.5194/hess-2018-447

Manuscript under review for journal Hydrol. Earth Syst. Sci.

Discussion started: 12 November 2018

(c) Author(s) 2018. CC BY 4.0 License.
Hydrology and

Earth System

Sciences

Discussions

(c) (i)

particle size distribution was discussed. For a given $U_{w}$, a set of eight collection efficiency points have been computed according to the slope $\lambda$ of the reference particle size distribution, which is correlated with the snowfall intensity measured by the gauge (equation 2).

The CFD results show that when $U_{w}$ is higher than $3 \mathrm{~m} / \mathrm{s}$, there is an abrupt increase of the $P_{S A} / P_{D F I R}$ scattering from $1 \mathrm{~mm} \mathrm{~h}^{-}$

$5{ }^{1}<S I_{S A}<1.5 \mathrm{~mm} \mathrm{~h}^{-1}$ (red points) to $0 \mathrm{~mm} \mathrm{~h}^{-1}<S I_{S A}<0.5 \mathrm{~mm} \mathrm{~h}^{-1}$ (blue points), associated with a decrease of the collection efficiency at a given wind speed (Fig. 10a). When the average wind speed is lower or equal to $3 \mathrm{~m} / \mathrm{s}$ the dependency of the $P_{S A} / P_{D F F}$ on the measured snowfall intensity becomes less significant meaning that even the smaller particles are mostly collected by the single Alter gauge. The latter result is not confirmed by the field measurements provided in Figure 1 that show a persistent scattering of $P_{S A} / P_{D F I R}$ at the lower wind speeds. Such behaviour has been already explained by Colli et al.

10 (2016b) that demonstrated the role of the airflow turbulence generated by the wind shield in the collection efficiency scattering by means of time-dependent CFD simulation. The same figures are not obtained by using time-averaged CFD simulations that do not represent the airflow time fluctuations, leading to the $P_{S A} / P_{D F I R}$ distribution of Figure 10 .

The results of the CFD simulations therefore highlight the physical dependency between the collection efficiency and the snowfall intensity measured by the gauge, and this dependency varies according to the wind speed. Figure 10b shows the CE

15 field observations for 10-min accumulation time categorized by snowfall intensity confirming the dependency between collected precipitation, measured intensity and wind speed.
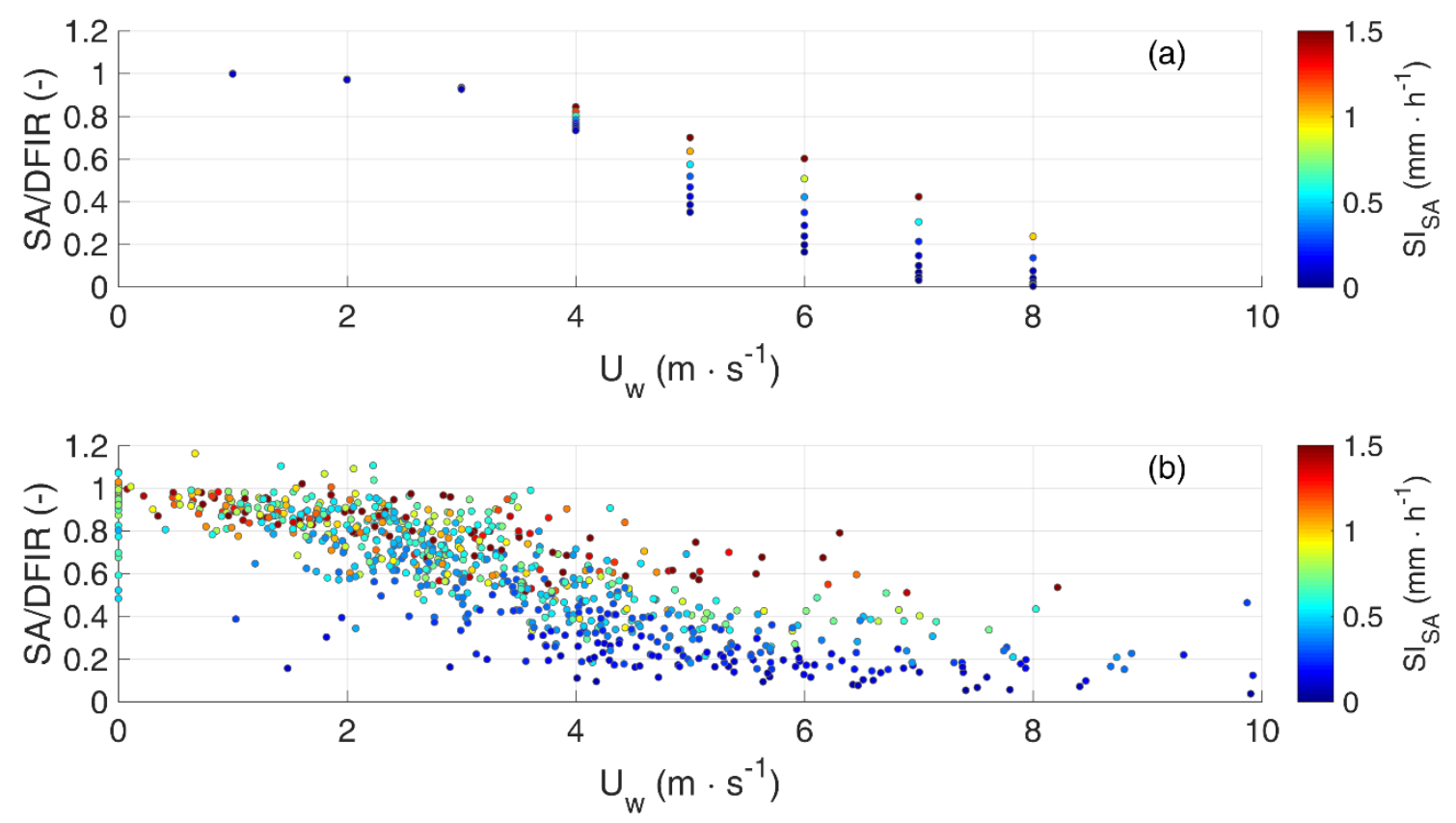

Figure 10: Collection efficiency $C E=P_{S A} / P_{D F I R}$ of the 10 min single Alter gauge measurements simulated by means of the timeaveraged CFD model (panel a) and actual 10 min measurements (panel b) made at the Marshall field site (CO, USA). Data are colour coded according to the measured snowfall intensity $S I_{S A}$, showing the clustering of the measurements. 
Hydrol. Earth Syst. Sci. Discuss., https://doi.org/10.5194/hess-2018-447

Manuscript under review for journal Hydrol. Earth Syst. Sci.

Discussion started: 12 November 2018

(c) Author(s) 2018. CC BY 4.0 License.
Hydrology and

Earth System

Sciences

Discussions

(c) (i)

The conceptual improvement achieved when the transfer function is parameterised according to the measured snowfall intensity is best visualised in the $S I_{S A} v s$. $S I_{R E F}$ scatter plot in Figure 11a where $S I_{R E F}$ is the reference snowfall intensity (assumed coincident with $S I_{D F I R}$ for the field data). In this graph, where the wind speed is colour coded according to the side

5 bar, the iso-CE lines would be linear (grey dotted lines) in the absence of a clear influence of the $S I_{S A}$ on the collection efficiency. However, this is not supported neither by the field data (white dots in panels b, c, d, e of Figure 11) nor by numerical simulations (solid coloured curves and diamonds in Figure 11a). Instead, a clear deviation from linearity is observed, showing that the collection efficiency increases far beyond linearity with the measured snowfall intensity, $S I_{S A}$, for any given wind speed. This deviation vanishes when $U_{w} \rightarrow 0$ and increases with the wind speed, therefore justifying the larger spread of collection efficiency values observed towards the right-hand side in Figure 10 (a and b).
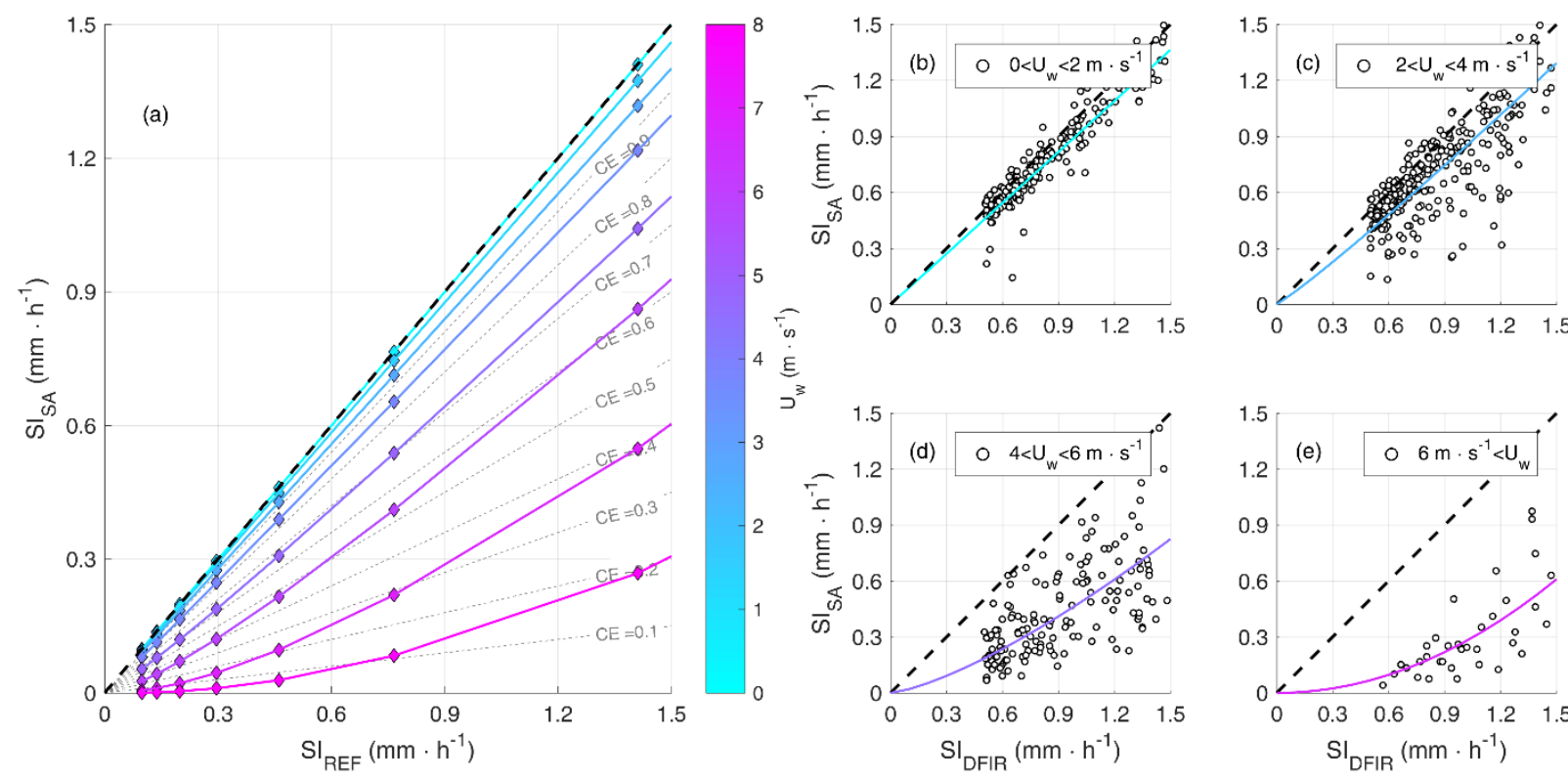

15 Figure 11: Collection efficiency deviation from linearity (grey dotted lines) when increasing the wind speed (colour coded according to the side bar) in the measured $S I_{S A}$ vs. reference $S I_{R E F}$ snowfall intensity plane. The deviation is evident in both the results of numerical simulation (solid coloured lines and diamonds in panel a) and field data (white circles in panels b, $\mathbf{c}$, d, e) although with residual dispersion. The field data is presented together with the $S I_{S A}=a S I_{D F I R}{ }^{b}$ power law regressions performed for the $U_{w}<2 \mathrm{~ms}^{-1}(a=0.90, b=1.00, r=0.98), 2<U_{w}<4 \mathrm{~ms}^{-1}(a=0.83, b=1.08, r=0.94), 4<U_{w}<6 \mathrm{~ms}^{-1}(a=0.47, b=1.37, r=0.84)$ and $6 \mathrm{~ms}^{-1}<$ $U_{w}(a=0.27, b=2.00, r=0.85)$ classes. 
Hydrol. Earth Syst. Sci. Discuss., https://doi.org/10.5194/hess-2018-447

Manuscript under review for journal Hydrol. Earth Syst. Sci.

Discussion started: 12 November 2018

(c) Author(s) 2018. CC BY 4.0 License.

\section{Conclusions}

The present analysis of recent WMO SPICE quality controlled $30 \mathrm{~min}$ accumulation data from the Marshall field-test site (CO, USA) revealed that the wind-induced undercatch of solid precipitation gauges is best correlated with the measured

5 snowfall intensity, rather than temperature, in addition to wind speed. Optimal curve fitting used to derive the transfer function for the GEONOR gauge in a single Alter shield and in a DFIR configuration indicates that accounting for snowfall intensity indeed reduces the scatter of the residuals.

This result is confirmed by the analysis of data from other field sites, such as CARE (Canada) and Haukeliseter (Norway), and shows a consistent behaviour under different climatological conditions. Recent results from Chubb et al. (2015) found

10 improved under-catch correction for an ETI weighing gauge for data collected in the Snowy Mountains of Australia. This supports our results and suggests that other snow gauges can benefit from this type of adjustment.

The physical basis for the improved parameterisation of the transfer function by using the measured snowfall intensity was shown through CFD modelling of the gauge snow collection process to be due to the correlation of large particles with high intensities. Large particles are preferentially collected by a snow gauge, even in strong wind, due to their higher fall velocity,

15 allowing them to break through streamlines of flow above the gauge and be collected. The CFD modelling was able to reproduce the collection efficiency pattern observed in the field providing strong evidence of the hypothesized behaviour.

The analysis of the optimal accumulation period of the snowfall measurements was based on the evaluation of the residual data scattering after applying a correction based on wind speed $U_{w}$ and environmental temperature $T$ and a correction based on $U_{w}$ and the measured snowfall intensity $S I_{S A}$. It has been observed that shorter accumulation intervals increase the

20 dependency of $C E$ on $S I_{S A}$ and a stronger benefit in using the proposed approach. On the other hand, it was also observed larger accumulation intervals are generally associated with a smaller residual scattering of the measurements. According to our analysis, the 10 min time interval may represent a trade-off point between the availability of correlated $S I_{S A}$ and $C E$ observations and the need of accumulating significant amounts of snowfall when lower precipitation intensities occur.

Overall, these findings provide an attractive method to improve operational measurements since no additional instrument, except for a wind sensor, is required to the derived the improved estimates of snow accumulation.

\section{Acknowledgements}

30 J.M Thériault funded by the Natural Research Council of Canada (NSERC) 
Hydrol. Earth Syst. Sci. Discuss., https://doi.org/10.5194/hess-2018-447

Manuscript under review for journal Hydrol. Earth Syst. Sci.

Discussion started: 12 November 2018

(c) Author(s) 2018. CC BY 4.0 License.

\section{References}

Alter, J.: Shielded storage precipitation gages. Mon. Wea. Rev., 65, 262-265, 1937.

Buisán, S. T., Earle, M. E., Collado, J. L., Kochendorfer, J., Alastrué, J., Wolff, M., Smith, C. D., and López-Moreno, J. I.: Assessment of snowfall accumulation underestimation by tipping bucket gauges in the Spanish operational network, Atmos. Meas. Tech., 10, 1079-1091, 2016.

Chubb, T., M.J. Manton, S.T. Siems, A.D. Peace, and Bilish, S.P.: Estimation of Wind-Induced Losses from a Precipitation Gauge Network in the Australian Snowy Mountains. J. Hydrometeor., 16, 2619-2638, 2015.

Colli, M., R. Rasmussen, J.M. Thériault, L.G. Lanza, C.B. Baker, and Kochendorfer J.: An Improved Trajectory Model to Evaluate the Collection Performance of Snow Gauges. J. Appl. Meteor. Climatol., 54, 1826-1836, 2015.

Colli, M., Lanza, L.G., Rasmussen, R.M. and Thèriault, J.M.: The collection efficiency of shielded and unshielded precipitation gauges. Part I: CFD airflow modelling. J. of Hydrometeorol., 17(1), pages 231-243, $2016 \mathrm{a}$.

Colli, M., Lanza, L.G., Rasmussen, R.M. and Thèriault, J.M.: The collection efficiency of shielded and unshielded precipitation gauges. Part II: modelling particle trajectories. J. of Hydrometeorol., 17(1), 245-255, 2016b.

Constantinescu, S., Krajewski, W., Ozdemir, C., Tokyay, T.: Simulation of flow around raingauges: Comparison of LES with RANS models. Journal of Advances in Water Resources 30, 43-58, 2006.

Eldred, M.S., Agarwal, H., Perez, V.M., Wojtkiewicz, S.F., Jr., and Renaud, J.E.: Investigation of Reliability Method Formulations in DAKOTA/UQ, Structure \& Infrastructure Engineering: Maintenance, Management, Life-Cycle Design \& Performance, Vol. 3, No. 3, pp. 199-213, 2007.

Folland, C. K.: Numerical models of the raingauge exposure problem, field experiments and an improved collector design. Q.J.R. Meteorol. Soc., 114: 1485-1516, 1988.

Gergely M. and Garrett,T.J.: Impact of the natural variability in snowflake diameter, aspect ratio, and orientation on modeled snowfall radar reflectivity. J. Geophys. Research, 121(20), 12,236-12,252, 2016.

Goodison, B., P. Louie, and Yang, D.: WMO solid precipitation measurement intercomparison: final report. WMO Tech. Document 872, World Meteorological Organization, Geneva, Switzerland, 1998.

Houze, R. A., P. V. Hobbs, and Herzegh,P.H.: Size distributions of precipitation particles in frontal clouds. J. Atmos. Sci., 36, 156-162, 1979.

Kochendorfer, J., Rasmussen, R., Wolff, M., Baker, B., Hall, M. E., Meyers, T., Landolt, S., Jachcik, A., Isaksen, K., Brækkan, R., and Leeper, R.: The quantification and correction of wind-induced precipitation measurement errors, Hydrol. Earth Syst. Sci., 21, 1973-1989, 2017a.

30 Kochendorfer, J., Nitu, R., Wolff, M., Mekis, E., Rasmussen, R., Baker, B., Earle, M. E., Reverdin, A., Wong, K., Smith, C. D., Yang, D., Roulet, Y.-A., Buisan, S., Laine, T., Lee, G., Aceituno, J. L. C., Alastrué, J., Isaksen, K., Meyers, T., Brækkan, R., Landolt, S., Jachcik, A., and Poikonen, A.: Analysis of single-Alter-shielded and unshielded measurements of mixed and solid precipitation from WMO-SPICE, Hydrol. Earth Syst. Sci., 21, 3525-3542, $2017 \mathrm{~b}$.

Kochendorfer, J., Nitu, R., Wolff, M., E. Mekis, R. Rasmussen, B. Baker and others: Testing and Development of

Transfer Functions for Weighing Precipitation Gauges in WMO-SPICE. Journal of Hydrology and Earth System Sciences Discussions, 2017, 1-25, 2017c. 
Hydrol. Earth Syst. Sci. Discuss., https://doi.org/10.5194/hess-2018-447

Manuscript under review for journal Hydrol. Earth Syst. Sci.

Discussion started: 12 November 2018

(c) Author(s) 2018. CC BY 4.0 License.

Hydrology and

Earth System

Sciences

Discussions

(c) (i)

Matrosov, S.Y., C. Campbell, D. Kingsmill, and E. Sukovich: Assessing Snowfall Rates from X-Band Radar Reflectivity Measurements. J. Atmos. Oceanic Technol., 26, 2324-2339, 2009.

Nespor, V., and B. Sevruk: Estimation of wind-induced error of rainfall gauge measurements using a numerical simulation. J. Atmos. Oceanic Technol., 16 (4), 450-464, 1999.

Nitu, R., and Coauthors: WMO intercomparison of instruments and methods for the measurement of solid precipitation and snow on the ground: Organization of the experiment. Preprints, TECO-2012: WMO Technical Conference on Meteorological and Environmental Instruments and Methods of Observations, Brussels, Belgium,WMO,10 pp., 2012.

Rasmussen and Coauthors: How well are we measuring snow: The NOAA/FAA/NCAR winter precipitation test bed. Bull. Amer. Meteor. Soc., 93, 811-829, 2012.

Reverdin, A.: Description of the Quality Control and Event Selection Procedures used within the WMO-SPICE project, Madrid, Spain, September, 2016.

Thériault, J., Rasmussen, R., Ikeda, K., Landolt, S.: Dependence of snow gauge collection efficiency on snowflake characteristics. Journal of Applied Meteorology and Climatology 51, 745-762, 2012.

Thériault, J.M., R. Rasmussen, E. Petro, J. Trépanier, M. Colli, and Lanza,L.G.: Impact of Wind Direction, Wind Speed, and Particle Characteristics on the Collection Efficiency of the Double Fence Intercomparison Reference. J. Appl. Meteor. Climatol., 54, 1918-1930, 2015.

Thom, A. S.: Momentum, mass and heat exchange of plant communities, in: Vegetation and the Atmosphere, Vol. 1, edited by: Monteith, J. L., Academic Press, London, 1975.

Wolff,M., K. Isaksen, A. Petersen-Øverleir, K. Ødemark, T. Reitan, and Bækkan R.: Derivation of a new continuous adjustment function for correcting wind-induced loss of solid precipitation: results of a norwegian field study. Hydrol. Earth Syst. Sci., 9(11), 10 043-10 084, 2014.

Yang, D., and Coauthors: Quantification of precipitation measurement discontinuity induced by wind shields on national gauges. Water Resour. Res., 35 (2), 491508, 1999. 